\title{
Ecological Approaches to Dental Caries Prevention: Paradigm Shift or Shibboleth?
}

\author{
Nebu Philip ${ }^{a}$ Bharat Suneja ${ }^{b}$ Laurence J. Walsh ${ }^{a}$ \\ a School of Dentistry, The University of Queensland, Brisbane, QLD, Australia; ${ }^{b}$ Baba Jaswant Singh Dental College \\ and Hospital, Ludhiana, India
}

\section{Keywords}

Biofilm ecology · Dental caries · Prevention

\begin{abstract}
Contemporary paradigms of dental caries aetiology focus on the ecology of the dental plaque biofilm and how local environmental factors can modulate this to cause disease. The crucial role that a healthy oral microbiome plays in preventing caries and promoting oral health is also being increasingly recognized. Based on these concepts, several ecological preventive approaches have been developed that could potentially broaden the arsenal of currently available caries-preventive measures. Many of these ecological approaches aim for long-term caries control by either disrupting cariogenic virulence factors without affecting bacterial viability, or include measures that can enhance the growth of health-associated, microbially diverse communities in the oral microbiome. This paper argues for the need to develop ecological preventive measures that go beyond conventional caries-preventive methods, and discusses whether these ecological approaches can be effective in reducing the severity of caries by promoting stable, health-associated oral biofilm communities.

(c) 2018 S. Karger AG, Basel
\end{abstract}

Oral health is integral to general well-being, with profound individual and societal implications that extend well beyond the functions of the craniofacial complex. Although largely preventable, diseases such as dental caries are major public health concerns, imposing a costly burden on health services. Traditional caries epidemiological measures do not adequately reflect the social impacts, economic costs, and health care system effects of the disease [Casamassimo et al., 2009].

At the individual level, control of dental caries remains largely dependent on twice-daily mechanical oral hygiene in the form of toothbrushing with fluoride dentifrices, a preventive approach that has been in place for over 50 years. Based on the current understanding of the dental caries process, several ecological preventive strategies have been developed or are currently under investigation, suggesting a future where caries prevention will not be narrowly focussed on fluoride therapies. This review will explore the rationale supporting the need for alternate methods of dental caries control, and will discuss the current status of some ecological approaches to biofilm modification and caries prevention.

\section{KARGER}

(c) 2018 S. Karger AG, Basel

E-Mail karger@karger.com

www.karger.com/cre
Nebu Philip

Room 6410, UQ Oral Health Centre

288 Herston Road

Brisbane, QLD 4006 (Australia)

E-Mail n.philip@uq.edu.au 


\section{Dental Caries: A Biofilm-Mediated Multifactorial Disease}

Dental caries belongs to a group of diseases that are considered "complex" or "multifactorial," with no single causation pathway, and therefore, are not amenable to simplistic preventive solutions such as the elimination of "one type of organism" or merely enhancing "tooth resistance" [Fejerskov, 2004]. Dental caries is now widely recognized to be an endogenous, biofilm-mediated disease that occurs when acidogenic/aciduric members of resident oral flora obtain a selective ecological advantage over other species, disrupting the homeostatic balance of the plaque biofilm and initiating the disease process [Marsh and Martin, 1999]. Modern molecular analyses and microbial culture techniques have demonstrated that an entire range of bacteria, not just mutans streptococci (MS) or lactobacilli (LB), can contribute to the caries process at different stages [Tanner et al., 2016], and that even fungi such as Candida albicans can significantly enhance the cariogenic virulence of plaque biofilms [Koo and Bowen, 2014]. An MS- or LB-dominated microbiome may be found only at the advanced stages of the disease, where the increased severity and frequency of biofilm acidification results in the oral microbiome becoming less microbially diverse [Takahashi and Nyvad, 2008]. Indeed, it is not the bacterial genotype per se but their shared phenotypic characteristics (being acidogenic and aciduric) that are more important for driving the microbial ecological shift that leads to dental caries [Takahashi and Nyvad, 2011].

While the ionic aspects of the dental caries process have been the focus of research for decades, new insights into the aetiology and microbial aspects of this biofilmmediated disease have engendered novel concepts and approaches for its prevention and control [ten Cate and Cummins, 2013]. A consensus is now emerging that caries-preventive measures should aim to not only correct the environmental pressures responsible for the plaque biofilm dysbiosis, but also help to maintain a healthy, microbially diverse, resident microbiome [Marsh et al., 2015]. These new approaches acknowledge the possibility that bacteria yet to be identified and cultured may participate in the caries process, and aligns with engaging in a more comprehensive approach towards preventing dental caries as a disease at the patient level [Walsh, 2011].

\section{Rationale for Newer Methods of Dental Caries Control}

\section{Ecological Strategies}

The historical focus in preventing and managing oral diseases was on eliminating dental plaque from teeth. However, contemporary evolving evidence is increasingly highlighting the beneficial aspects of a healthy oral microbiome [Kilian et al., 2016]. Commensal plaque microflora have a symbiotic relationship with the host, not only acting as a barrier to opportunistic pathogens, but also carrying out metabolic processes that benefit the host [He et al., 2011; Schlafer et al., 2017]. Acute infections of the oral mucosa are rare because of the interplay between the host immune system and microbial symbionts [Zaura et al., 2014]. Likewise, the pro- and anti-inflammatory activities of resident bacteria help maintain homeostasis in the oral cavity [Devine et al., 2015]. A moderate amount of healthy plaque has also been shown to prevent erosive enamel lesions and hypersensitivity [Honorio et al., 2010].

Based on this changed understanding of the importance of a healthy oral microbiome, caries-preventive strategies should ideally take an ecological approach to the holobiont. Indiscriminate or "shotgun" suppression of almost the entire oral biota, without understanding the overall effects on plaque ecology, is unlikely to have longterm success in controlling the disease [Caufield et al., 2001]. Instead, preventive and curative products should either specifically target cariogenic bacteria without affecting other resident microflora, or they should inhibit virulence factors (e.g., glucan synthesis or acid production) rather than bacterial viability [ten Cate and Zaura, 2012]. Measures that enhance colonization of health-promoting microbial communities can also help in correcting the ecological imbalance in cariogenic biofilms. The advantage of such an approach is that the impacts of low $\mathrm{pH}$ environments generated by acidogenic organisms can be counterbalanced by ammonia production from other bacteria. Following an ecological approach to caries prevention can potentially preserve the favourable effects that the host derives from the resident oral microbiome, while reducing cariogenic virulence factors that are responsible for plaque biofilm dysbiosis.

\section{Aetiological Factors}

The control and prevention of any disease should preferably focus on the aetiological factors involved. For dental caries, this would be the periodic disorganization of the oral plaque biofilm by mechanical oral hygiene, along 
with dietary modification to reduce exposure to fermentable carbohydrates [Cury and Tenuta, 2008]. Unfortunately, individual oral hygiene measures have only a limited impact in caries prevention [Bellini et al., 1981; Nyvad, 2003; Hujoel et al., 2006]. It has also been suggested that toothbrushing has been effective in preventing caries mainly because it brings fluoride into the oral cavity at regular intervals, rather than any particular efficiency in disrupting cariogenic plaque biofilms [ten Cate and Zaura, 2012]. Dietary modification, which requires individuals to restrict their exposure to sucrose and other fermentable substrates, is particularly difficult to achieve in present-day society where cariogenic foods are easily available [Duggal and Van Loveren, 2001]. Furthermore, restriction of sucrose intake alone is unlikely to completely prevent dental caries if frequent intake of other starches persisted [Bradshaw and Lynch, 2013]. Thus, while minimizing the aetiological factors contributing to the disease is critical, additional preventive measures commensurate with individual risk status may still be required in many segments of the population.

\section{Caries Epidemiology}

For a long time, dental caries was a pandemic that affected children and adults almost universally. The landmark discovery of fluoride as an agent that could prevent dental caries, and the widespread use of fluoride-based caries-preventive programmes, have been responsible for the significant reductions seen in caries prevalence of developed countries in the latter half of the 20th century [Fejerskov, 2004]. However, the latest Global Burden of Disease report revealed that untreated caries in permanent teeth still remains the most common human disease condition worldwide [Kassebaum et al., 2015]. Doubts have also been expressed on whether the earlier decline in caries prevalence has continued into this new century [Gimenez et al., 2016]. Recent caries prevalence studies in the USA and Australia indicate tooth decay may in fact be increasing again [Dye et al., 2007; Chrisopoulos et al., 2016]. A similar trend has been seen in countries such as Norway and Iceland, which had initially shown the biggest improvements, but are now registering increases in caries experience [Haugejorden and Birkeland, 2005; Agustsdottir et al., 2010]. The flattening of prevalence rates that has occurred even in dentally aware populations where individuals commonly brush their teeth with fluoridated dentifrices is concerning and underscores the need to develop additional caries-preventive measures that are synergistic with or complementary to fluoride.

Ecological Caries-Preventive Approaches

\section{Fluoride Alone May Not Be Sufficient}

While fluoride is a highly effective and economical agent for dental caries prevention and will remain the mainstay of any caries-preventive programme, it must be recognized that in many situations fluoride alone may not be sufficient. Even with regular fluoride use, carious lesions can still develop when there are more than 6 dietary sugar exposures per day [Duggal et al., 2001; CcahuanaVasquez et al., 2007]. The ready availability of cariogenic snack foods and drinks in the modern consumer culture can overwhelm the benefits of community water fluoridation and daily use of a fluoride dentifrice. The limit to the repair potential of fluoride could partly explain the reversal of the caries decline being observed in contemporary epidemiological reports from developed countries [Agustsdottir et al., 2010; Dye et al., 2017].

The cariostatic actions of fluoride are largely attributed to its physiochemical ability to inhibit enamel demineralization and enhance remineralization [Cury and Tenuta, 2008]. Recent laboratory studies have confirmed the notion that under appropriate conditions fluoride ions can also influence critical MS virulence factors, significantly reducing acidogenicity, aciduricity, and glucan formation [Domon-Tawaraya et al., 2013; Pandit et al., $2013,2015]$. Metabolome analysis of plaque biofilms has demonstrated that fluoride can repress acid production in vivo too [Takahashi and Washio, 2011]. However, questions still remain on the extent to which these antibacterial mechanisms contribute towards caries-preventive effects. A recent study showed that the brief fluoride exposure from toothpastes or mouthwashes could not sustain anti-acid production activity, with the biofilms recovering acidogenicity over time regardless of the fluoride concentration used [Dang et al., 2016]. Concerns have also arisen regarding the emergence of micro-organisms that are more resistant to the effects of fluoride on microbial metabolism [Mitsuhata et al., 2014].

Preventive approaches that combine fluoride with other protective agents have been advocated to enhance the ability of fluoride to modify biofilms and diminish the cariogenic bacterial challenge [Li et al., 2015]. Fluoride-antimicrobial combinations have been recommended based on the 2-part rationale that fluoride can reduce the critical $\mathrm{pH}$ at which dissolution starts, while effective antimicrobial agents can decrease the depth of the Stephan curve $\mathrm{pH}$ drop following consumption of fermentable carbohydrates [Øgaard, 2000]. Randomized controlled trials (RCTs) have shown that fluoride-chlorhexidine interventions significantly reduced bacterial load and $\mathrm{pH}$ drop from glucose metabolism [Giertsen and Scheie, 1995], and 
most importantly, lowered caries increment in high-risk groups [Featherstone et al., 2012]. Sytematic reviews have also found high-quality evidence that fluoride-triclosan toothpastes give a small improvement in reducing coronal caries compared to conventional fluoride dentifrices [Blinkhorn et al., 2009; Riley and Lamont, 2013]. However, the use of such broad-spectrum antimicrobial agents may not be ideal, as the aim of antimicrobial treatment in caries prevention should preferably be to modify the plaque biofilm ecology by weakening cariogenic virulence factors rather than eliminating microflora.

An alternative to the fluoride-antimicrobial approach is combining fluoride with agents that promote an overall community-wide microbial shift by encouraging the growth of health-associated bacteria, thereby beneficially rebalancing the biofilm ecology and potentially resulting in better long-term dental caries control. Among such biofilm-modifying oral products, there is now sufficient evidence supporting fluoride-arginine combinations as a new standard of care for caries prevention [ten Cate and Cummins, 2013; Zheng et al., 2015]. Likewise, a dentifrice containing enzymes and proteins was shown to significantly shift the ecology of the oral microbiome resulting in a community with a stronger association to health [Adams et al., 2017].

\section{Caries Risk}

Over time, the distribution of caries in the community has changed from a disease that was pandemic in society, to now being endemic in specific risk groups. A crosssectional study concluded that $75 \%$ of the caries-risk burden tends to reside in $25-40 \%$ of the population [Macek et al., 2004]. Likewise, there is evidence for genetic differences that exist with respect to caries susceptibility [Bretz et al., 2005; Opal et al., 2015], with not everyone in a population group benefiting to the same extent from traditional caries-preventive programmes [ten Cate, 2013]. The pattern of dental caries has also changed over the years, from a rapidly progressing disease of childhood, to a slowly progressing disease that can occur or persist throughout adulthood and old age [Lagerweij and van Loveren, 2015]. Data from contemporary population studies have revealed that carious lesions are also increasingly localized to specific tooth sites [Anderson, 2002]. In children and adolescents, occlusal surfaces are the sites most likely to have experienced caries [Carvalho, 2014; Carvalho et al., 2016]. The increasing life expectancy of dentition also means that older adults with exposed root surfaces are at greater risk of experiencing root caries during their lifetime [Gati and Vieira, 2011]. With fluoride known to exert its cariostatic actions primarily on smooth enamel surfaces, susceptible occlusal/root surfaces remain relatively predisposed to acid dissolution [ten Cate, 2009]. Caries-preventive strategies must therefore go beyond conventional methods (personal oral hygiene, fluoride dentifrices, and limiting sugar exposures) to better protect at-risk surfaces in at-risk patients.

\section{Fluoride Safety}

The US Centers for Disease Control and Prevention ranked community water fluoridation as one of the 10 great public health achievements of the 20th century. Despite continued broad support within the dental profession worldwide, the polarized debate on the safety of fluorides used for caries prevention still continues in sections of the popular and scientific press. Recent reports can only add to the alarmist picture for sections of the general public who are not informed readers of the scientific literature on this topic. For example, a 2012 systematic review and meta-analysis concluded that high fluoride exposure may lower IQ levels in children [Choi et al., 2012], a finding which attracted media attention and triggered the inclusion of fluoride amongst chemicals classified as developmental neurotoxicants [Grandjean and Landrigan, 2014]. There are however a number of concerns with how the 2012 review was conducted - all selected studies were from China, fluoride exposure came from multiple sources not just drinking water, the definition of "high" fluoride levels varied widely, and the probability of confounding as covariates was not controlled. The authors themselves were extremely conservative, only concluding that "our results support the possibility of adverse effects" advocating future research to evaluate dose-response relations based on individual-level measures of exposure over time. However, these caveats are universally overlooked when studies are reported in the media, and this fans extremist views on the safety of fluoride used for caries prevention.

Additionally, dental fluorosis from excessive intake of fluoride during the period of tooth formation is a persisting concern that is raised by antifluoride lobbyists. While emphasizing that fluoride is safe when used at the recommended levels for community water fluoridation or dentifrices, behaviours such as swallowing large amounts of dentifrice are not. In modern times there are also now opportunities for "halo" exposure from various other sources of fluoride, which has triggered downward revision of recommended levels for community water fluoridation (from $0.7-1.2$ to $0.7 \mathrm{mg} / \mathrm{L}$ ), to ensure that the risk for dental fluorosis does not increase [EPA, 2011]. 
Ecological caries-preventive approaches synergistic with fluoride can potentially allow dental products to be designed with lower concentrations of fluoride and these could be useful for caries prevention in infants and young children, as well as for patients reluctant to use oral care products with high fluoride concentrations.

\section{Ecological Approaches to Caries Prevention}

\section{Antimicrobial Peptides}

Antimicrobial peptides (AMPs) are a heterogeneous group of molecules with unique antimicrobial characteristics that have great potential for controlling bacterial infections and modifying biofilms. AMPs have a broad range of antibacterial, antiviral, and antifungal activity mediated by selectively interacting electrostatically with negatively charged components of cell membrane phospholipids, resulting in membrane permeabilization and disruption, leading to cell death [Koczulla and Bals, 2003]. To escape the actions of bilayer-disruptive AMPs would entail changing membrane composition and organization, a "costly" process in evolutionary terms, meaning that AMPs have very low resistance rates compared to common antibiotics [Zasloff, 2002]. Besides naturally secreted salivary AMPs (lactoferrin, cathelicidins, histatins, defensins), a number of AMPs have been synthesized in the laboratory, and these include specific anticaries peptides that have shown the potential to modify plaque biofilms and inhibit dental caries.

The specifically targeted antimicrobial peptide (STAMP) is a synthetic fusion peptide with 2 independent functional domains, consisting of a Streptococcus . mutans-selective "targeting domain" designated as C16, and a "killing domain" designated as G2. C16 is derived from a fragment of the $S$. mutans competence stimulating peptide (CSP), while G2 is derived from a broad-spectrum antimicrobial peptide [Eckert et al., 2012]. C16G2 had antimicrobial mechanisms similar to traditional AMPs, and critically, its membrane-disrupting activity specifically targets $S$. mutans from multispecies biofilms without affecting closely related non-cariogenic oral streptococci [Eckert et al., 2006; Kaplan et al., 2011]. More recently, an in vitro study on human saliva-derived polymicrobial biofilms was able to demonstrate that treatment with C16G2 not only eliminated S. mutans, but also resulted in a more benign oral microbial community with increased populations of health-associated bacteria and fewer harmful Gram-negative bacteria [Guo et al., 2015]. C16G2 is recognized by the US Food and Drug Adminis-

Ecological Caries-Preventive Approaches tration as an investigational new drug for dental caries prevention and has successfully completed phase II clinical trials, where it was delivered to patients in the form of a dental gel loaded in trays.

Another promising anticaries AMP is a synthetic a-helical antimicrobial decapeptide designated KSL-W, which can selectively destabilize the cell membranes of cariogenic bacteria including S. mutans, S. sobrinus, and L. acidophilus [Na et al., 2007; Leung et al., 2009]. This peptide resits enzymatic degradation in human saliva for $1 \mathrm{~h}$, and the potential use of KSL-W as an antibiofilm agent in a chewing gum formulation has been suggested [Faraj et al., 2007; Na et al., 2007]. More recently, a hydroxyapatite-binding AMP was designed, based on the fusion of specific hydroxyapatite-binding heptapeptide (HBP7) with KSL-W, and this bioconjugate was shown to have improved oral retention and antibacterial efficacy [Huang et al., 2016b]. Other AMPs that have shown in vitro antimicrobial activity against cariogenic bacteria and inhibited oral biofilm formation include a synthetic peptide called L-K6 (derived from the naturally occurring peptide temporin-1CEb), a short synthetic amphiphilic peptide known as 1018, and an amphipathic $\alpha$-helical peptide containing only 12 amino acids named GH12 [Shang et al., 2014; Wang et al., 2015; Tu et al., 2016].

Limitations of AMPs include their potential toxicity, susceptibility to proteases, high cost of peptide production, and the reduced cationic activity of most AMPs in physiological fluids like saliva. With regard to their use for dental caries prevention, questions still remain on whether anticaries AMPs will be able to function against a background of excessive acid production often seen in high caries-risk individuals [Maltz and Beighton, 2012]. Before any clinical recommendations can be made, it will be essential to test such agents in a caries-conducive oral environment, and to evaluate whether the desired outcome of reduced caries increment in at-risk population groups can be achieved.

\section{Probiotics}

The term probiotics refers to "live micro-organisms, which, when administered in adequate amounts, confer a health benefit on the host" [Teughels et al., 2008], and is based on the Noble-prize-winning pioneering work of Metchnikoff [1907] for maintaining a healthy gut flora. This concept of implanting a harmless effector strain into the host's microflora to maintain or restore a natural microbiome by inhibition of pathogenic micro-organisms is attractive and has also been used to support health-associated microbes or restore diversity in the oral plaque bio- 
film. The mechanisms by which probiotics re-establish ecological balance in oral biofilms are not fully understood, but probiotic bacteria are believed to have both local and systemic effects [Meurman, 2005]. The local anticaries effects may include competitive inhibition with cariogenic bacteria for nutrition or adhesive surfaces [Terai et al., 2015], selective co-aggregation of MS without disturbing other oral flora [Twetman et al., 2009; Lang et al., 2010], and bacteriocin-producing probiotics targeting MS [Burton et al., 2013]. The most commonly used and studied probiotics belong to the Lactobacillus and Bifidobacterium bacterial genera, although not all their strains have the same efficacy in the inhibition of $S$. mutans growth or biofilm formation [Schwendicke et al., 2017].

Evidence supporting the application of probiotics for preventing dental caries is controversial, with recent reports suggesting potential harmful effects for some probiotic bacterial strains [Gruner et al., 2016]. One of the problems identified in using probiotics for caries prevention is that the commonly available Lactobacillus and Bifidobacterium probiotic bacteria are themselves acidogenic and aciduric, and could contribute to the caries process if such bacteria are allowed to colonize the oral cavity [Maltz and Beighton, 2012]. Recent in vitro biofilm studies have confirmed this apprehension with different strains such as Lactobacillus salivarius W24 [Pham et al., 2009], Lactobacillus rhamnosus GG [Schwendicke et al., 2014a], Bifidobacteria animalis lactis BB12 [Schwendicke et al., 2014b], Lactobacillus rhamnosus LB21 [Fernández et al., 2015], and Lactobacillus acidophilus LA-5 [Schwendicke et al., 2017] which have all been shown to lower biofilm pH. In fact, some Lactobacillus and Bifidobacterium strains have greater cariogenic attributes than even MS [Beighton et al., 2010]. Thus, while displacing S. $m u$ tans from plaque biofilms may in principle be desirable, substituting them for even more cariogenic bacteria will not be useful [Schwendicke et al., 2014a]. Some of the non-acidogenic alternatives to Lactobacillus and Bifidobacterium that have shown promising early results include S. salivarius M18 [Burton et al., 2013], heat-inactivated BB12 [Schwendicke et al., 2014b], and Weissella cibaria CMU [Jang et al., 2016].

Another limitation with the traditional use of gut-associated Lactobacillus and Bifidobacterium probiotic species to promote oral health is that these non-oral bacterial strains may not efficiently colonize the oral niche, which is vital for the long-term success of probiotics [López-López et al., 2017]. Even the use of a bacteriocinproducing strain of $S$. salivarius may not succeed, as $S$. salivarius, while a typical member of the oral soft tissue flora, has limited ability to colonize tooth surfaces. However, very recently 2 natural oral commensal species, Streptococcus dentisani and Streptococcus A12 that were isolated from the supragingival plaque of caries-free individuals, have demonstrated promising probiotic effects against dental caries. Both these "active colonizers" have a double probiotic action, as they can not only inhibit the growth of MS, but also moderate plaque $\mathrm{pH}$ through their arginolytic actions [Huang et al., 2016a; López-López et al., 2017].

The current decade has seen a number systematic reviews and meta-analyses evaluating the effectiveness of using traditional gut-associated probiotics for caries prevention. A meta-analysis of studies with surrogate caries markers (MS and/or LB counts) concluded that these probiotics significantly decreased MS counts, but there were insufficient data on whether caries increment was reduced as well [Laleman et al., 2014]. A similar inference was also reached by a qualitative systematic review of probiotic caries studies, concluding that clinical recommendations would be premature without more comprehensive RCTs showing an actual reduction in individual caries experience [Twetman and Keller, 2012]. Relatively few RCTs of oral probiotics have used clinical dental caries indicators to prove the efficacy of probiotics in preventing or treating dental caries [Näse et al., 2001; StecksénBlicks et al., 2009; Burton et al., 2013; Taipale et al., 2013]. A comprehensive systematic review utilizing evidence from these RCTs concluded that current evidence is insufficient for recommending probiotics in controlling dental caries [Gruner et al., 2016].

Taken together, currently available data indicate that while traditional probiotic bacteria may have a beneficial effect on the gut flora and systemic health, a beneficial and clinically significant effect on the oral flora is yet to be demonstrated with sufficient rigor. However, observations from 2 major clinical trials in children [Näse et al., 2001; Stecksén-Blicks et al., 2009] support the intriguing concept of a "metabolic domino effect," with reductions in caries risk seen to be accompanied by improvements in general health. Particularly promising for caries prevention is the move away from gut-associated probiotic bacteria to resident oral probiotic strains, such as the $2 S$. mutans-antagonistic bacterial species $S$. dentisani and A12. Further evidence on the ability of these oral probiotics to inhibit dental caries is awaited with interest.

\section{Prebiotics}

The prebiotic approach involves feeding resident microbiota with specific nutrients to create conditions that 
favour the growth and dominance of healthy bacteria in the biofilm. The nutritional stimulation of endogenous beneficial oral flora to restore microbial balance and promote oral health has been validated in mixed species models [Slomka et al., 2017]. Oral prebiotic substrates that are especially valuable to prevent caries include arginine, arginine-rich peptides, and urea, as these foods when metabolized create alkalizing effects that counteract the acidogenic environment created by cariogenic bacteria. Many commensal bacteria are able to use arginine or urea to generate ammonia by the arginine deaminase system or urease enzymes, respectively [Bradshaw and Marsh, 1998; Nascimento et al., 2009]. Multiple studies have shown that bacterial production of alkaline metabolites such as ammonia can play a major role in biofilm $\mathrm{pH}$ homeostasis and beneficially alter the de-/remineralization equilibrium [Burne and Marquis, 2000; Burne et al., 2012; Nascimento et al., 2014]. A substantial body of evidence from microbiological, genetic, biochemical analyses, and clinical studies has now accumulated confirming that the modulation of the alkalinogenic potential of dental biofilms is a promising strategy for caries control [Liu et al., 2012].

The preventive potential of oral alkali production has resulted in the development of commercial oral care products that utilize arginine to promote a healthy resident oral microbiome. In vitro biofilm experiments found that fluoride-arginine combinations synergistically inhibited S. mutans but enriched S. sanguinis growth within multispecies biofilms, while maintaining a "streptococcal pressure" against the potential growth of oral anaerobe Porphyromonas gingivalis in the alkalized biofilm [Zheng et al., 2015]. Fluoride-arginine combinations can also suppress exopolysaccharide production, thus targeting another critical virulence factor for cariogenic biofilms [Zheng et al., 2015]. Human in situ studies and several double-blinded RCTs using a fluoride dentifrice containing $1.5 \%$ arginine and an insoluble calcium compound have shown significantly greater protection against carious lesions than a fluoride dentifrice alone [Cantore et al., 2013; Kraivaphan et al., 2013; Srisilapanan et al., 2013; Yin et al., 2013; Petersen et al., 2015]. A systematic review and meta-analysis of the anticaries effects of argininecontaining dentifrice formulations concluded that arginine products provided a superior preventive effect over matched formulations containing fluoride alone [Li et al., 2015]. Other authors have been more conservative in their conclusions, either citing insufficient evidence in support of a caries-preventive effect for arginine, or expressing concerns over the higher cost of arginine-fluo-

Ecological Caries-Preventive Approaches ride dentifrices versus any additional caries-preventive effect these may provide [Ástvaldsdóttir et al., 2016]. However, the preponderance of evidence does seem to suggest that the arginolysis is an effective approach to improve oral health and balance the microbial ecology.

\section{Sugar Polyols}

Sucrose has been designated as the "arch criminal" in the caries process for a long time [Newbrun, 1967], and the search for alternative non-fermentable sweeteners has attracted much attention. Data collected from in vitro and in vivo studies indicate that such sugar substitutes can exhibit potential anticaries effects through a number of different mechanisms [Matsukubo and Takazoe, 2006]. Xylitol, a naturally occurring 5-carbon sugar polyol, is the non-nutritive sweetener that has been most extensively researched over the past 4 decades for its potential cariostatic effects. Xylitol inhibits MS growth by disrupting their energy production processes, leading to a futile energy cycle and cell death [Marttinen et al., 2012]. Although not all MS strains were inhibited by xylitol in this manner, even xylitol-resistant bacteria were found to be less virulent after xylitol treatment [Trahan, 1995]. The predominant delivery vehicle for xylitol has been chewing gums, with xylitol dentifrices, candies, lozenges, and mouthrinses also having been used with varying degrees of success. A substantial body of evidence suggests that 5-6 g of xylitol per day delivered over 3 exposures are needed for worthwhile anticaries effects [Milgrom et al., 2009]. Among other sugar polyols, erythritol has been attracting increasing attention as it is has been shown to be more effective than xylitol and sorbitol, and importantly, its anticaries effects were shown to persist for up to 3 years [Honkala et al., 2014; de Cock et al., 2016; Falony et al., 2016].

Despite an immense body of literature, the caries-preventive effects of xylitol products remain inconclusive because of inconsistent study outcomes. While numerous studies have indicated xylitol has beneficial effects on surrogate end points (MS levels, plaque $\mathrm{pH}$, acid production), evidence for worthwhile reductions in caries experience remains equivocal, and there is a need for more double-blind placebo-controlled RCTs, focussing on optimal dosage, delivery vehicle, and possible synergism with other preventive agents [Twetman, 2009; Milgrom et al., 2012]. In fact, the more recent data conclude that there is limited evidence to show xylitol is effective in the fight against dental caries. A double-blind cluster RCT using xylitol gummy bears found that polyol consumption did not provide any additional benefit over other car- 
ies-preventive measures [Lee et al., 2015]. Recent Cochrane systematic reviews also found only very-low- to low-quality evidence on xylitol effectiveness which was not sufficient to determine whether xylitol-containing products can prevent caries in infants, children or adults [Duane, 2015; Riley et al., 2015]. Other issues that limit the usefulness of sugar polyols include their high costs and low compliance in high-risk patients because of the need for daily long-term use [Gold, 2016].

\section{Quorum-Sensing Targets}

Another approach that may maintain and support a healthy oral plaque ecology is to interfere with the fundamental cell-cell communications system between biofilm bacteria. This process of quorum sensing (QS) is mediated through small diffusible hormone-like molecules (pheromones) and their specific receptors. For MS, the stress-dependent QS system is primarily comprised of the $\mathrm{CSP}$ and its ComD/ComE 2-component signal transduction system for communication between biofilm cells of the same species, while interspecies signalling is mediated via the autoinducer- 2 molecule produced by LuxS [Senadheera and Cvitkovitch, 2008]. The CSP-mediated QS system in S. mutans affects biofilm formation, acidogenicity, aciduricity, genetic transformation, bacteriocin production, stress response, and the ability to produce persister phenotypes [Leung et al., 2015]. Targeting QS signalling pathways could provide a promising avenue in the development of novel therapeutics to alter cariogenic biofilms. As QS is not directly involved in processes essential for bacterial growth, targeting QS will allow less virulent bacteria to remain in the biofilm and will also not impose selective pressures that can lead to the development of antibiotic resistance [Rasmussen and Givskov, 2006].

Interfering with CSP signalling systems has been shown to inactivate a wide range of bacteriocins and mutacins that play an important role in the sustained existence of $S$. mutans in the dental plaque [Cvitkovitch et al., 2003; Qi et al., 2004]. The addition of an exogenous CSP can disrupt signalling events of $S$. mutans and induce cell death [Qi et al., 2005]. Another novel QS-modifying compound, 3-Oxo-N, was seen to significantly minimize lactic acid accumulation without affecting biofilm growth even in the presence of fermentable sugars, representing a promising agent for maintaining a healthy, non-cariogenic microbial ecology in dental plaque [Janus et al., 2016].

\section{Natural Products}

Natural products include secondary metabolites or phytochemicals derived from plants, fruits, herbs, or spices. They offer a rich source of structurally diverse molecules with a wide range of biological activities and could prove useful as alternative or adjunctive anticaries agents [Jeon et al., 2011]. Potential cariostatic mechanisms identified include inhibition of bacterial growth or acid production, inhibition of glucan synthesis by interfering with glucosyltransferase (Gtf) activity, and inhibition of bacterial adhesion [Ferrazzano et al., 2011; Jeon et al., 2011].

Polyphenols from propolis (apigenin and $t t$-farnesol) and cranberry proanthocyanidins have been shown to exert useful ecological effects on the plaque biofilm. Apigenin is a potent inhibitor of water-insoluble glucan synthesis, while $t t$-farnesol disrupts $S$. mutans membrane permeability and acid production [Koo and Jeon, 2009]. An animal study found a combination of these 2 phytochemicals with fluoride suppressed dental caries without affecting the viability of normal oral flora, being as potent as a fluoride-chlorhexidine control in caries inhibition, but without the broad antibacterial action of the control [Koo et al., 2005]. Similarly, cranberry proanthocyanidins, which lack significant biocidal activity, can modify plaque biofilms by reducing acidogenicity and glucan synthesis, and these surrogate end points were also translated into cariostatic effects in vivo [Koo et al., 2010]. A number of other polyphenol compounds have been found to be effective in killing S. mutans, with the minimal inhibitory concentrations of some bioactive molecules like xanthorrhizol (from Curcuma xanthorrhiza) or macelignan (from Myristica fragrans) almost comparable to chlorhexidine [Hwang et al., 2000; Chung et al., 2006]. While most of the tested anticaries phytochemicals showed growth-inhibitory or anti-adhesive effects, a potentially interesting natural agent in caries prevention is Galla chinensis, which was able to beneficially regulate the de-/remineralization balance of dental hard tissues [Cheng et al., 2015].

An analysis of how phytochemical research has impacted oral care in the period from 2000 to 2015 found that despite many in vitro, in vivo, and clinical studies testing natural products derived from plants, only $11 \%$ of studies were in phase IV clinical trials [Freires and Rosalen, 2016] Similar conclusions were reached in a systematic review of the anticaries effects of essential oils and their isolated constituents, which found that most studies were conducted in the laboratory, and did not provide botanical characterization or compositional data on the natural product being tested [Freires et al., 2015]. Natural products remain a largely unexplored source of effective and non-toxic antibiofilm molecules that could potential- 
ly be used in combination with fluoride as useful alternatives to traditional microbiocides like chlorhexidine or triclosan [Jeon et al., 2011]. However, future research needs to focus on translational approaches to advance the development of effective anticaries products containing phytochemicals or essential oils.

\section{Replacement Therapy with "Designer" Bacteria}

Modifying dental plaque by replacing $S$. mutans, a member of the normal microbiota, with a less virulent effector strain has been an established concept for many years [Hillman, 1978]. The rationale for bacterial replacement therapy against dental caries is that relatively avirulent strains of MS are most likely to occupy the same ecological niche in plaque as their more cariogenic counterparts thereby reducing the overall cariogenicity of the plaque biofilm [Sun et al., 2009].

A number of "designer" bacteria have been studied for bacteriotherapy against cariogenic biofilms including a glucan synthesis-defective mutant of $S$. mutans, variants of $S$. salivarius (TOVE-R), and a recombinant alkali-generating ureolytic S. mutans strain [Tanzer et al., 1974, 1985; Clancy et al., 2000]. The most extensive research in using genetically modified bacteria for preventing dental caries used a wild-type $S$. mutans strain that naturally produces an antibiotic called mutacin 1140 capable of killing all other strains of $S$. mutans [Hillman, 2002]. This strain was genetically modified by deleting the open reading frame for lactate dehydrogenase, to yield a viable strain called BCS3-L1 that still produced wild-type levels of mutacin 1140, but notably produced no lactic acid [Hillman et al., 2000]. In laboratory and animal models, the BCS3-L1 strain proved to have significantly reduced cariogenic potential. It persistently and pre-emptively colonized tooth sites normally occupied by wild-type $S$. mutans strains, with no reported adverse effects [Hillman et al., 2000]. To overcome safety issues and to enable the altered strain to be implanted into human oral biofilms for clinical trials, additional genetic modifications of BCS3-L1 were made, which could facilitate its rapid elimination should an adverse event manifest itself. This strain was designated as A2JM and was extensively tested to assure its safe use in phase I clinical trials [Hillman et al., 2007].

It has also been suggested that hypocariogenic strains exhibiting only defects in acid production are unlikely to compete successfully with wild-type strains for initial plaque locations, and on this principle, an S. mutans strain that was deficient in the $g c r R$ gene was genetically engineered for bacterial replacement therapy [Sun et al.,
2009; Pan et al., 2013]. The $g c r R$ gene functions as a negative transcriptional regulator of the $g b p C$ gene, which encodes the glucan-binding lectin, an adhesin that is ubiquitous on S. mutans surfaces and plays an important role in initial bacterial aggregation and adhesion to tooth surfaces. The MS-gcrR-def mutant bacteria showed reduced acid production, out-competed wild $S$. mutans strains with its strong early colonization ability, and lowered caries incidence in vivo [Pan et al., 2013].

Modulation of oral plaque biofilms with genetically engineered "designer" bacteria has great potential through fostering a healthy oral environment, which prevents the dominance of cariogenic bacteria. A single treatment regimen could lead to persistent colonization by the effector strain affording lifelong protection, with minimal need for patient compliance. Whilst there have been encouraging results with genetically modified strains, the concept of replacement therapy needs to be tested for effectiveness in highly cariogenic environments. Even if successful, the widespread acceptance of genetically engineered "designer" bacteria may prove to be difficult for emotional, ethical, and legal reasons.

\section{Other Approaches}

In addition to the strategies discussed above, several alternative approaches for modifying plaque biofilm ecology are under investigation including using compounds that specifically affect bacterial virulence proteins [Horst et al., 2012], calcium phosphate-osteopontin particles that can inhibit biofilm formation and reduce the fall in $\mathrm{pH}$ without affecting bacterial viability [Schlafer et al., 2017], nanoparticles [Allaker and Douglas, 2015], graphene oxide [He et al., 2015], and ceramic water [Nomura et al., 2017].

\section{Conclusions}

There is no doubt that fluoride will continue to be the mainstay of any caries prevention protocol as it still remains the most effective and economical protective agent against dental caries. However, fluoride alone may not offer complete protection against the disease, and it is generally recognized that the effectiveness of fluoride could be enhanced when combined with additional cariostatic agents [NIH, 2001]. Moreover, current paradigms emphasize the importance of maintaining a healthy and stable oral plaque biofilm for long-term disease control. One way to do this is to limit or exclude refined sugars from the diet; however, within the constraints of present- 
day consumer culture, behavioural dietary changes are difficult to achieve and sustain. Adopting ecological preventive measures can help in correcting the disturbed plaque ecology and drive the advent and persistence of a symbiotic oral microbiome. These could be valuable tools in achieving long-term dental caries control, allowing the clinician to shift to a biological model for the management of the disease.

It is imperative that the effectiveness of ecological preventive approaches be evaluated for success in individuals who consume a conventional diet containing a fairly high level of sugars before any clinical recommendations are made [Beighton, 2009]. Furthermore, rather than surrogate end points like lower MS levels or reduced acid production, the critically important outcome for all new caries-preventive measures will be whether they can ensure a significant reduction in individual caries experience.

\section{Disclosure Statement}

The authors declare no potential conflicts of interest with respect to the authorship and/or publication of this article.

\section{Author Contributions}

N.P. conceived and drafted the manuscript with support and input from B.S. L.J.W. critically reviewed and revised the manuscript. N.P., B.S., and L.J.W. approved the final manuscript as submitted.

\section{References}

Adams SE, Arnold D, Murphy B, Carroll P, Green AK, Smith AM, Marsh PD, Chen T, Marriott RE, Brading MG: A randomised clinical study to determine the effect of a toothpaste containing enzymes and proteins on plaque oral microbiome ecology. Sci Rep 2017;7:43344.

Agustsdottir H, Gudmundsdottir H, Eggertsson $\mathrm{H}$, Jonsson SH, Gudlaugsson JO, Saemundsson SR, Eliasson ST, Arnadottir IB, Holbrook WP: Caries prevalence of permanent teeth: a national survey of children in Iceland using ICDAS. Community Dent Oral Epidemiol 2010;38:299-309.

Allaker RP, Douglas ICW: Non-conventional therapeutics for oral infections. Virulence 2015;6:196-207.

Anderson M: Risk assessment and epidemiology of dental caries: review of the literature. Pediatr Dent 2002;24:377-385.

Ástvaldsdóttir Á, Naimi-Akbar A, Davidson T, Brolund A, Lintamo L, Attergren Granath A, Tranæus S, Östlund P: Arginine and caries prevention: a systematic review. Caries Res 2016;50:383-393.

Beighton D: Can the ecology of the dental biofilm be beneficially altered? Adv Dent Res 2009;21: 69-73.

Beighton D, Al-Haboubi M, Mantzourani M, Gilbert SC, Clark D, Zoitopoulos L, Gallagher JE: Oral Bifidobacteria: caries-associated bacteria in older adults. J Dent Res 2010;89:970-974.

Bellini HT, Arneberg P, von der Fehr FR: Oral hygiene and caries. A review. Acta Odontol Scand 1981;39:257-265.

Blinkhorn A, Bartold PM, Cullinan MP, Madden TE, Marshall RI, Raphael SL, Seymour GJ: Is there a role for triclosan/copolymer toothpaste in the management of periodontal disease? Br Dent J 2009;207:117-125.
Bradshaw DJ, Lynch RJM: Diet and the microbial aetiology of dental caries: New paradigms. Int Dent J 2013;63:64-72.

Bradshaw DJ, Marsh PD: Analysis of pH-driven disruption of oral microbial communities in vitro. Caries Res 1998;32:456-462.

Bretz WA, Corby PM, Schork NJ, Robinson MT, Coelho M, Costa S, Melo Filho MR, Weyant RJ, Hart TC: Longitudinal analysis of heritability for dental caries traits. J Dent Res 2005; 84:1047-1051.

Burne RA, Marquis RE: Alkali production by oral bacteria and protection against dental caries. FEMS Microbiol Lett 2000;193:1-6.

Burne RA, Zeng L, Ahn SJ, Palmer SR, Liu Y, Lefebure T, Stanhope MJ, Nascimento MM: Progress dissecting the oral microbiome in caries and health. Adv Dent Res 2012;24:77-80.

Burton JP, Drummond BK, Chilcott CN, Tagg JR, Thomson WM, Hale JDF, Wescombe PA: Influence of the probiotic Streptococcus salivarius strain M18 on indices of dental health in children: a randomized double-blind, placebo-controlled trial. J Med Microbiol 2013;62: 875-884.

Cantore R, Petrou I, Lavender S, Santarpia P, Liu Z, Gittins E, Vandeven M, Cummins D, Sullivan R, Utgikar N: In situ clinical effects of new dentifrices containing $1.5 \%$ arginine and fluoride on enamel de- and remineralization and plaque metabolism. J Clin Dent 2013; 24(Spec No A):A32-A44.

Carvalho JC: Caries process on occlusal surfaces: evolving evidence and understanding. Caries Res 2014;48:339-346.

Carvalho JC, Dige I, Machiulskiene V, Qvist V, Bakhshandeh A, Fatturi-Parolo C, Maltz M: Occlusal caries: Biological approach for its diagnosis and management. Caries Res 2016;50: 527-542.
Casamassimo PS, Thikkurissy S, Edelstein BL, Maiorini E: Beyond the dmft: the human and economic cost of early childhood caries. J Am Dent Assoc 2009;140:650-657.

Caufield PW, Dasanayake AP, Li Y: The antimicrobial approach to caries management. J Dent Educ 2001;65:1091-1095.

Ccahuana-Vasquez RA, Tabchoury CP, Tenuta LM, Del Bel Cury AA, Vale GC, Cury JA: Effect of frequency of sucrose exposure on dental biofilm composition and enamel demineralization in the presence of fluoride. Caries Res 2007;41:9-15.

Cheng L, Li J, He L, Zhou X: Natural products and caries prevention. Caries Res 2015;49(suppl 1):38-45.

Choi AL, Sun G, Zhang Y, Grandjean P: Developmental fluoride neurotoxicity: a systematic review and meta-analysis. Environ Health Perspect 2012;120:1362-1368.

Chrisopoulos S, Harford JE, Ellershaw A: Oral health and dental care in Australia: key facts and figures 2015. Cat. No. Den 229. Canberra, Australian Institute of Health and Welfare, 2016.

Chung JY, Choo JH, Lee MH, Hwang JK: Anticariogenic activity of macelignan isolated from Myristica fragrans (nutmeg) against Streptococcus mutans. Phytomedicine 2006;13:261266.

Clancy KA, Pearson S, Bowen WH, Burne RA: Characterization of recombinant, ureolytic Streptococcus mutans demonstrates an inverse relationship between dental plaque ureolytic capacity and cariogenicity. Infect Immun 2000;68:2621-2629.

Cury JA, Tenuta LMA: How to maintain a cariostatic fluoride concentration in the oral environment. Adv Dent Res 2008;20:13-16. 
Cvitkovitch DG, Li YH, Ellen RP: Quorum sensing and biofilm formation in streptococcal infections. J Clin Invest 2003;112:1626-1632.

Dang MH, Jung JE, Lee DW, Song KY, Jeon JG: Recovery of acid production in Streptococcus mutans biofilms after short-term fluoride treatment. Caries Res 2016;50:363-371.

De Cock P, Mäkinen K, Honkala E, Saag M, Kennepohl E, Eapen A: Erythritol is more effective than xylitol and sorbitol in managing oral health endpoints. Int J Dent 2016;2016: 9868421.

Devine DA, Marsh PD, Meade J: Modulation of host responses by oral commensal bacteria. J Oral Microbiol 2015;7:26941.

Domon-Tawaraya H, Nakajo K, Washio J, Ashizawa T, Ichino T, Sugawara H, Fukumoto S, Takahashi N: Divalent cations enhance fluoride binding to Streptococcus mutans and Streptococcus sanguinis cells and subsequently inhibit bacterial acid production. Caries Res 2013;47:141-149.

Duane B: Xylitol and caries prevention. Evid Based Dent 2015;16:37-38.

Duggal MS, Toumba KJ, Amaechi BT, Kowash MB, Higham SM: Enamel demineralization in situ with various frequencies of carbohydrate consumption with and without fluoride toothpaste. J Dent Res 2001;80:1721-1724.

Duggal MS, van Loveren C: Dental considerations for dietary counselling. Int Dent J 2001;51: 408-412.

Dye BA, Tan S, Smith V, Lewis BG, Barker LK, Thornton-Evans G, Eke PI, Beltran-Aguilar ED, Horowitz AM, Li CH: Trends in oral health status: United States, 1988-1994 and 1999-2004. Vital Health Stat 11 2007;1-92.

Dye BA, Vargas CM, Fryar CD, Ramos-Gomez F, Isman R: Oral health status of children in Los Angeles County and in the United States, 1999-2004. Community Dent Oral Epidemiol 2017;45:135-144.

Eckert R, He J, Yarbrough DK, Qi F, Anderson MH, Shi W: Targeted killing of Streptococcus mutans by a pheromone-guided "smart" antimicrobial peptide. Antimicrob Agents Chemother 2006;50:3651-3657.

Eckert R, Sullivan R, Shi W: Targeted antimicrobial treatment to re-establish a healthy microbial flora for long-term protection. Adv Dent Res 2012;24:94-97.

EPA: EPA and HHS announce new scientific assessments and actions on fluoride: agencies working together to maintain benefits of preventing tooth decay while preventing excessive exposure. 2011. http://yosemite.epa.gov/ opa/admpress.nsf/bd4379a92ceceeac852573 5900400c27/86964af577c37ab285257811005 a8417! OpenDocument.

Falony G, Honkala S, Runnel R, Olak J, Nõmmela R, Russak S, Saag M, Mäkinen PL, Mäkinen K, Vahlberg T, Honkala E: Long-term effect of erythritol on dental caries development during childhood: a posttreatment survival analysis. Caries Res 2016;50:579-588.
Faraj JA, Dorati R, Schoubben A, Worthen D, Selmin F, Capan Y, Leung K, DeLuca PP: Development of a peptide-containing chewing gum as a sustained release antiplaque antimicrobial delivery system. AAPS Pharm Sci Tech 2007;8:26.

Featherstone JD, White JM, Hoover CI, RapozoHilo M, Weintraub JA, Wilson RS, Zhan L, Gansky SA: A randomized clinical trial of anticaries therapies targeted according to risk assessment (caries management by risk assessment). Caries Res 2012;46:118-129.

Fejerskov O: Changing paradigms in concepts on dental caries: consequences for oral health care. Caries Res 2004;38:182-191.

Fernández CE, Giacaman RA, Tenuta LM, Cury JA: Effect of the probiotic Lactobacillus rhamnosus LB21 on the cariogenicity of Streptococcus mutans UA159 in a dual-species biofilm model. Caries Res 2015;49:583-590.

Ferrazzano GF, Amato I, Ingenito A, Zarrelli A, Pinto G, Pollio A: Plant polyphenols and their anti-cariogenic properties: a review. Molecules 2011;16:1486-1507.

Freires I, Denny C, Benso B, de Alencar S, Rosalen P: Antibacterial activity of essential oils and their isolated constituents against cariogenic bacteria: a systematic review. Molecules 2015; 20:7329.

Freires IA, Rosalen PL: How natural product research has contributed to oral care product development? A critical view. Pharm Res 2016;33:1311-1317.

Gati D, Vieira AR: Elderly at greater risk for root caries: a look at the multifactorial risks with emphasis on genetics susceptibility. Int J Dent 2011;2011:647168.

Giertsen E, Scheie AA: Effects of chlorhexidinefluoride mouthrinses on viability, acidogenic potential, and glycolytic profile of established dental plaque. Caries Res 1995;29:181-187.

Gimenez T, Bispo BA, Souza DP, Vigano ME, Wanderley MT, Mendes FM, Bonecker M, Braga MM: Does the decline in caries prevalence of Latin American and Caribbean children continue in the new century? Evidence from systematic review with meta-analysis. PLoS One 2016;11:e0164903.

Gold J: Consumption of xylitol gummy bears may not provide additional caries prevention for school children. J Evid Based Dent Pract 2016; 16:70-72.

Grandjean P, Landrigan PJ: Neurobehavioural effects of developmental toxicity. Lancet Neurol 2014;13:330-338.

Gruner D, Paris S, Schwendicke F: Probiotics for managing caries and periodontitis: systematic review and meta-analysis. J Dent 2016;48:1625.

Guo L, McLean JS, Yang Y, Eckert R, Kaplan CW, Kyme P, Sheikh O, Varnum B, Lux R, Shi W, He X: Precision-guided antimicrobial peptide as a targeted modulator of human microbial ecology. Proc Natl Acad Sci USA 2015;112: 7569-7574.
Haugejorden O, Birkeland JM: Analysis of the ups and downs of caries experience among Norwegian children aged five years between 1997 and 2003. Acta Odontol Scand 2005;63:115122.

He J, Zhu X, Qi Z, Wang C, Mao X, Zhu C, He Z, Li M, Tang Z: Killing dental pathogens using antibacterial graphene oxide. ACS Appl Mater Interfaces 2015;7:5605-5611.

He X, Hu W, He J, Guo L, Lux R, Shi W: Community-based interference against integration of Pseudomonas aeruginosa into human salivary microbial biofilm. Mol Oral Microbiol 2011; 26:337-352.

Hillman JD: Lactate dehydrogenase mutants of Streptococcus mutans: isolation and preliminary characterization. Infect Immun 1978;21: 206-212.

Hillman JD: Genetically modified Streptococcus mutans for the prevention of dental caries. Antonie Van Leeuwenhoek 2002;82:361-366.

Hillman JD, Brooks TA, Michalek SM, Harmon CC, Snoep JL, van der Weijden CC: Construction and characterization of an effector strain of Streptococcus mutans for replacement therapy of dental caries. Infect Immun 2000;68: 543-549.

Hillman JD, Mo J, McDonell E, Cvitkovitch D, Hillman CH: Modification of an effector strain for replacement therapy of dental caries to enable clinical safety trials. J Appl Microbiol 2007;102:1209-1219.

Honkala S, Runnel R, Saag M, Olak J, Nõmmela R, Russak S, Mäkinen PL, Vahlberg T, Falony G, Mäkinen K, Honkala E: Effect of erythritol and xylitol on dental caries prevention in children. Caries Res 2014;48:482-490.

Honorio HM, Rios D, Santos CF, Buzalaf MA, Machado MA: Influence of dental plaque on human enamel erosion: in situ/ex vivo study. Oral Health Prev Dent 2010;8:179-184.

Horst JA, Pieper U, Sali A, Zhan L, Chopra G, Samudrala R, Featherstone JDB: Strategic protein target analysis for developing drugs to stop dental caries. Adv Dent Res 2012;24:8693.

Huang X, Palmer S, Ahn S-J, Richards VP, Williams ML, Nascimento MM, Burne RA: Characterization of a highly arginolytic Streptococcus species that potently antagonizes Streptococcus mutans. Appl Environ Microbiol 2016a;82:2187-2201.

Huang ZB, Shi X, Mao J, Gong SQ: Design of a hydroxyapatite-binding antimicrobial peptide with improved retention and antibacterial efficacy for oral pathogen control. Sci Rep 2016b;6:38410.

Hujoel PP, Cunha-Cruz J, Banting DW, Loesche WJ: Dental flossing and interproximal caries: a systematic review. J Dent Res 2006;85:298305

Hwang JK, Shim JS, Pyun YR: Antibacterial activity of xanthorrhizol from Curcuma xanthorrhiza against oral pathogens. Fitoterapia 2000;71:321-323. 
Jang H-J, Kang M-S, Yi S-H, Hong J-Y, Hong S-P: Comparative study on the characteristics of Weissella cibaria CMU and probiotic strains for oral care. Molecules 2016;21:1752.

Janus MM, Crielaard W, Zaura E, Keijser BJ, Brandt BW, Krom BP: A novel compound to maintain a healthy oral plaque ecology in vitro. J Oral Microbiol 2016;8:10.

Jeon JG, Rosalen PL, Falsetta ML, Koo H: Natural products in caries research: current (limited) knowledge, challenges and future perspective. Caries Res 2011;45:243-263.

Kaplan CW, Sim JH, Shah KR, Kolesnikova-Kaplan A, Shi W, Eckert R: Selective membrane disruption: mode of action of C16G2, a specifically targeted antimicrobial peptide. Antimicrob Agents Chemother 2011;55:34463452.

Kassebaum NJ, Bernabe E, Dahiya M, Bhandari B, Murray CJ, Marcenes W: Global burden of untreated caries: a systematic review and metaregression. J Dent Res 2015;94:650-658.

Kilian M, Chapple ILC, Hannig M, Marsh PD, Meuric V, Pedersen AML, Tonetti MS, Wade WG, Zaura E: The oral microbiome - an update for oral healthcare professionals. Br Dent J 2016;221:657-666.

Kleinberg I: A mixed-bacteria ecological approach to understanding the role of the oral bacteria in dental caries causation: an alternative to Streptococcus mutans and the specificplaque hypothesis. Crit Rev Oral Biol Med 2002;13:108-125.

Koczulla AR, Bals R: Antimicrobial peptides: current status and therapeutic potential. Drugs 2003;63:389-406.

Koo H, Bowen WH: Candida albicans and Streptococcus mutans: a potential synergistic alliance to cause virulent tooth decay in children. Future Microbiol 2014;9:1295-1297.

Koo H, Duarte S, Murata RM, Scott-Anne K, Gregoire S, Watson GE, Singh AP, Vorsa N: Influence of cranberry proanthocyanidins on formation of biofilms by Streptococcus mutans on saliva-coated apatitic surface and on dental caries development in vivo. Caries Res 2010;44:116-126

Koo H, Jeon JG: Naturally occurring molecules as alternative therapeutic agents against cariogenic biofilms. Adv Dent Res 2009;21:63-68.

Koo H, Schobel B, Scott-Anne K, Watson G, Bowen WH, Cury JA, Rosalen PL, Park YK: Apigenin and tt-farnesol with fluoride effects on S. mutans biofilms and dental caries. J Dent Res 2005;84:1016-1020.

Kraivaphan P, Amornchat C, Triratana T, Mateo LR, Ellwood R, Cummins D, DeVizio W, Zhang YP: Two-year caries clinical study of the efficacy of novel dentifrices containing $1.5 \%$ arginine, an insoluble calcium compound and 1,450 ppm fluoride. Caries Res 2013;47:582-590.

Lagerweij MD, van Loveren C: Declining caries trends: are we satisfied? Curr Oral Health Rep 2015;2:212-217.
Laleman I, Detailleur V, Slot DE, Slomka V, Quirynen $\mathrm{M}$, Teughels $\mathrm{W}$ : Probiotics reduce mutans streptococci counts in humans: a systematic review and meta-analysis. Clin Oral Investig 2014;18:1539-1552.

Lang C, Bottner M, Holz C, Veen M, Ryser M, Reindl A, Pompejus M, Tanzer JM: Specific Lactobacillus/mutans streptococcus co-aggregation. J Dent Res 2010;89:175-179.

Lee W, Spiekerman C, Heima M, Eggertsson H, Ferretti G, Milgrom P, Nelson S: The effectiveness of xylitol in a school-based clusterrandomized clinical trial. Caries Res 2015;49: 41-49.

Leung V, Ajdic D, Koyanagi S, Levesque CM: The formation of Streptococcus mutans persisters induced by the quorum-sensing peptide pheromone is affected by the LexA regulator. J Bacteriol 2015;197:1083-1094.

Leung KP, Abercrombie JJ, Campbell TM, Gilmore KD, Bell CA, Faraj JA, DeLuca PP: Antimicrobial peptides for plaque control. Adv Dent Res 2009;21:57-62.

Li J, Huang Z, Mei L, Li G, Li H: Anti-caries effect of arginine-containing formulations in vivo: a systematic review and meta-analysis. Caries Res 2015;49:606-617.

Liu Y-L, Nascimento M, Burne RA: Progress toward understanding the contribution of alkali generation in dental biofilms to inhibition of dental caries. Int J Oral Sci 2012;4:135-140.

López-López A, Camelo-Castillo A, Ferrer MD, Simon-Soro Á, Mira A: Health-associated niche inhabitants as oral probiotics: the case of Streptococcus dentisani. Front Microbiol 2017;8:379.

Macek MD, Heller KE, Selwitz RH, Manz MC: Is 75 percent of dental caries really found in 25 percent of the population? J Public Health Dent 2004;64:20-25.

Maltz M, Beighton D: Multidisciplinary research agenda for novel antimicrobial agents for caries prevention and treatment. Adv Dent Res 2012;24:133-136.

Marttinen AM, Ruas-Madiedo P, Hidalgo-Cantabrana C, Saari MA, Ihalin RA, Soderling EM: Effects of xylitol on xylitol-sensitive versus xylitol-resistant Streptococcus mutans strains in a three-species in vitro biofilm. Curr Microbiol 2012;65:237-243

Marsh PD, Head DA, Devine DA: Ecological approaches to oral biofilms: control without killing. Caries Res 2015;49(suppl 1):46-54.

Marsh PD, Martin MV: The resident oral microflora; in Marsh PD, Martin VM (eds): Oral Microbiology. Woburn, Reed Educational and Professional Publishing, 1999, pp 7-33.

Matsukubo T, Takazoe I: Sucrose substitutes and their role in caries prevention. Int Dent J 2006;56:119-130.

Metchnikoff E: Lactic acid as inhibiting intestinal putrefaction; in Metchnikoff E, Mitchell PC (eds): The Prolongation of Life: Optimistic Studies. London, Heinemann, 1907, pp 161183.
Meurman JH: Probiotics: do they have a role in oral medicine and dentistry? Eur J Oral Sci 2005;113:188-196.

Milgrom P, Ly KA, Rothen M: Research findings on xylitol and the development of xylitol vehicles to address public health needs. Adv Dent Res 2009;21:10-25.

Milgrom P, Söderling EM, Nelson S, Chi DL, Nakai Y: Clinical evidence for polyol efficacy. Adv Dental Res 2012;24:112-116.

Mitsuhata C, Puteri MM, Ohara Y, Tatsukawa N, Kozai K: Possible involvement of enolase in fluoride resistance in Streptococcus mutans. Pediatr Dent J 2014;24:12-16.

Na DH, Faraj J, Capan Y, Leung KP, DeLuca PP: Stability of antimicrobial decapeptide (KSL) and its analogues for delivery in the oral cavity. Pharm Res 2007;24:1544-1550.

Näse L, Hatakka K, Savilahti E, Saxelin M, Pönkä A, Poussa T, Korpela R, Meurman JH: Effect of long-term consumption of a probiotic bacterium, Lactobacillus rhamnosus GG, in milk on dental caries and caries risk in children. Caries Res 2001;35:412-420.

Nascimento MM, Browngardt C, Xiaohui X, Klepac-Ceraj V, Paster BJ, Burne RA: The effect of arginine on oral biofilm communities. Mol Oral Microbiol 2014;29:45-54.

Nascimento MM, Gordan VV, Garvan CW, Browngardt CM, Burne RA: Correlations of oral bacterial arginine and urea catabolism with caries experience. Oral Microbiol Immunol 2009;24:89-95.

Newbrun E: Sucrose, the arch criminal of dental caries. Odontol Rev 1967;18:373-386.

NIH: Diagnosis and management of dental caries throughout life. NIH Consensus Statement 2001;18:1-23.

Nomura R, Yoneyama R, Naka S, Otsugu M, Ogaya Y, Hatakeyama R, Morita Y, Maruo J, Matsumoto-Nakano M, Yamada O, Nakano K: The in vivo inhibition of oral biofilm accumulation and Streptococcus mutans by ceramic water. Caries Res 2017;51:58-67.

Nyvad B: The role of oral hygiene; in Fejerskov O, Kidd EAM (eds): Dental Caries: The Disease and Its Clinical Management. Copenhagen, Blackwell Munksgaard, 2003, pp 171-177.

Øgaard B: Oral microbiological changes, longterm enamel alterations due to decalcification, and caries prophylactic aspects; in Brantley WA, Eliades T (eds): Orthodontic Materials. Scientific and Clinical Aspects. Stuttgart, Thieme, 2000, pp 123-124.

Opal S, Garg S, Jain J, Walia I: Genetic factors affecting dental caries risk. Aust Dent J 2015;60: 2-11.

Pan W, Mao T, Xu Q-A, Shao J, Liu C, Fan M: A new gcrR-deficient Streptococcus mutans mutant for replacement therapy of dental caries. Sci World J 2013;2013:460202.

Pandit S, Cai JN, Jung JE, Jeon JG: Effect of 1-minute fluoride treatment on potential virulence and viability of a cariogenic biofilm. Caries Res 2015;49:449-457. 
Pandit S, Kim HJ, Song KY, Jeon JG: Relationship between fluoride concentration and activity against virulence factors and viability of a cariogenic biofilm: in vitro study. Caries Res 2013;47:539-547.

Petersen PE, Hunsrisakhun J, Thearmontree A, Pithpornchaiyakul S, Hintao J, Jurgensen N, Ellwood RP: School-based intervention for improving the oral health of children in southern Thailand. Community Dent Health 2015;32:44-50.

Pham LC, van Spanning RJ, Roling WF, Prosperi AC, Terefework Z, Ten Cate JM, Crielaard W, Zaura E: Effects of probiotic Lactobacillus salivarius W24 on the compositional stability of oral microbial communities. Arch Oral Biol 2009;54:132-137.

Qi F, Kreth J, Lévesque CM, Kay O, Mair RW, Shi W, Cvitkovitch DG, Goodman SD: Peptide pheromone induced cell death of Streptococcus mutans. FEMS Microbiol Lett 2005;251: 321-326.

Qi F, Merritt J, Lux R, Shi W: Inactivation of the ciaH gene in Streptococcus mutans diminishes mutacin production and competence development, alters sucrose-dependent biofilm formation, and reduces stress tolerance. Infect Immun 2004;72:4895-4899.

Rasmussen TB, Givskov M: Quorum sensing inhibitors: a bargain of effects. Microbiology 2006;152:895-904.

Riley P, Lamont T: Triclosan/copolymer containing toothpastes for oral health. Cochrane Database Syst Rev 2013;12:CD010514.

Riley P, Moore D, Ahmed F, Sharif MO, Worthington HV: Xylitol-containing products for preventing dental caries in children and adults. Cochrane Database Syst Rev 2015; 26:CD010743.

Schlafer S, Ibsen CJS, Birkedal H, Nyvad B: Calcium-phosphate-osteopontin particles reduce biofilm formation and $\mathrm{pH}$ drops in in situ grown dental biofilms. Caries Res 2017;51: 26-33.

Schwendicke F, Dörfer C, Kneist S, Meyer-Lueckel H, Paris S: Cariogenic effects of probiotic Lactobacillus rhamnosus GG in a dental biofilm model. Caries Res 2014a;48:186-192.

Schwendicke F, Horb K, Kneist S, Dörfer C, Paris S: Effects of heat-inactivated Bifidobacterium BB12 on cariogenicity of Streptococcus mutans in vitro. Arch Oral Biol 2014b;59:13841390.

Schwendicke F, Korte F, Dörfer CE, Kneist S, Fawzy El-Sayed K, Paris S: Inhibition of Streptococcus mutans growth and biofilm formation by probiotics in vitro. Caries Res 2017;51: $87-95$.

Senadheera D, Cvitkovitch DG: Quorum sensing and biofilm formation by Streptococcus mutans; in Utsumi R (ed): Bacterial Signal Transduction: Networks and Drug Targets. New York, Springer, 2008, pp 178-188.
Shang D, Liang H, Wei S, Yan X, Yang Q, Sun Y: Effects of antimicrobial peptide L-K6, a temporin $-1 \mathrm{CEb}$ analog on oral pathogen growth, Streptococcus mutans biofilm formation, and anti-inflammatory activity. Appl Microbiol Biotechnol 2014;98:8685-8695.

Slomka V, Hernandez-Sanabria E, Herrero ER, Zaidel L, Bernaerts K, Boon N, Quirynen M, Teughels W: Nutritional stimulation of commensal oral bacteria suppresses pathogens: the prebiotic concept. J Clin Periodontol 2017;44:344-352.

Srisilapanan P, Korwanich N, Yin W, Chuensuwonkul C, Mateo LR, Zhang YP, Cummins D, Ellwood RP: Comparison of the efficacy of a dentifrice containing $1.5 \%$ arginine and 1,450 ppm fluoride to a dentifrice containing 1,450 ppm fluoride alone in the management of early coronal caries as assessed using quantitative light-induced fluorescence. J Dent 2013; 41(suppl 2):29-34.

Stecksén-Blicks C, Sjöström I, Twetman S: Effect of long-term consumption of milk supplemented with probiotic Lactobacilli and fluoride on dental caries and general health in preschool children: A cluster-randomized study. Caries Res 2009;43:374-381.

Sun J-H, Xu Q-A, Fan M-W: A new strategy for the replacement therapy of dental caries. Med Hypotheses 2009;73:1063-1064.

Taipale T, Pienihäkkinen K, Alanen P, Jokela J, Söderling E: Administration of Bifidobacterium animalis subsp. lactis BB-12 in early childhood: a post-trial effect on caries occurrence at four years of age. Caries Res 2013;47:364372.

Takahashi N, Nyvad B: Caries ecology revisited: microbial dynamics and the caries process. Caries Res 2008;42:409-418.

Takahashi N, Nyvad B: The role of bacteria in the caries process: ecological perspectives. J Dent Res 2011;90:294-303.

Takahashi N, Washio J: Metabolomic effects of xylitol and fluoride on plaque biofilm in vivo. J Dent Res 2011;90:1463-1468.

Tanner AC, Kressirer CA, Faller LL: Understanding caries from the oral microbiome perspective. J Calif Dent Assoc 2016;44:437-446.

Tanzer JM, Freedman ML, Fitzgerald RJ, Larson RH: Diminished virulence of glucan synthesis-defective mutants of Streptococcus mutans. Infect Immun 1974;10:197-203.

Tanzer JM, Kurasz AB, Clive J: Inhibition of ecological emergence of mutans streptococci naturally transmitted between rats and consequent caries inhibition by Streptococcus salivarius TOVE- $\mathrm{R}$ infection. Infect Immun 1985;49:76-83.

Ten Cate JM: The need for antibacterial approaches to improve caries control. Adv Dent Res 2009;21:8-12.
Ten Cate JM: Contemporary perspective on the use of fluoride products in caries prevention. Br Dent J 2013;214:161-167.

Ten Cate JM, Cummins D: Fluoride toothpaste containing $1.5 \%$ arginine and insoluble calcium as a new standard of care in caries prevention. J Clin Dent 2013;24:79-87.

Ten Cate JM, Zaura E: The numerous microbial species in oral biofilms: how could antibacterial therapy be effective? Adv Dent Res 2012; 24:108-111.

Terai T, Okumura T, Imai S, Nakao M, Yamaji K, Ito M, Nagata T, Kaneko K, Miyazaki K, Okada A, Nomura Y, Hanada N: Screening of probiotic candidates in human oral bacteria for the prevention of dental disease. PLoS One 2015; 10:e0128657.

Teughels W, Van Essche M, Sliepen I, Quirynen M: Probiotics and oral healthcare. Periodontol 2000 2008;48:111-147.

Trahan L: Xylitol: a review of its action on mutans streptococci and dental plaque - its clinical significance. Int Dent J 1995;45:77-92.

Tu H, Fan Y, Lv X, Han S, Zhou X, Zhang L: Activity of synthetic antimicrobial peptide GH12 against oral streptococci. Caries Res 2016;50:48-61

Twetman L, Larsen U, Fiehn NE, Stecksen-Blicks C, Twetman S: Coaggregation between probiotic bacteria and caries-associated strains: an in vitro study. Acta Odontol Scand 2009;67: 284-288.

Twetman S: Current controversies - is there merit? Adv Dent Res 2009;21:48-52.

Twetman S, Keller MK: Probiotics for caries prevention and control. Adv Dent Res 2012;24: 98-102.

Walsh LJ: New paradigms for assessing caries risk and lesion activity. Auxiliary 2011;21:28-33.

Wang Z, de la Fuente-Núñez C, Shen Y, Haapasalo M, Hancock REW: Treatment of oral multispecies biofilms by an anti-biofilm peptide. PLoS One 2015; 10:e132512.

Yin W, Hu DY, Li X, Fan X, Zhang YP, Pretty IA, Mateo LR, Cummins D, Ellwood RP: The anti-caries efficacy of a dentifrice containing $1.5 \%$ arginine and $1,450 \mathrm{ppm}$ fluoride as sodium monofluorophosphate assessed using quantitative light-induced fluorescence (QLF). J Dent 2013;41(suppl 2):22-28.

Zasloff M: Antimicrobial peptides of multicellular organisms. Nature 2002;415:389-395.

Zaura E, Nicu EA, Krom BP, Keijser BJF: Acquiring and maintaining a normal oral microbiome: current perspective. Front Cell Infect Microbiol 2014;4:85.

Zheng X, Cheng X, Wang L, Qiu W, Wang S, Zhou Y, Li M, Li Y, Cheng L, Li J, Zhou X, Xu $\mathrm{X}$ : Combinatorial effects of arginine and fluoride on oral bacteria. J Dent Res 2015;94:344353. 